\title{
European Myeloma Network perspective on CAR T-cell therapies for multiple myeloma
}

Haematologica 2021

Volume 106(8):2054-2065

\section{Correspondence: \\ BENEDETTO BRUNO \\ benedetto.bruno@unito.it \\ Received: December 7, 2020. \\ Accepted: March 11, 2021. \\ Pre-published: April 1, 2021.}

https://doi.org/10.3324/haematol.2020.276402

\section{(C)2021 Ferrata Storti Foundation}

Material published in Haematologica is covered by copyright. All rights are reserved to the Ferrata Storti Foundation. Use of published material is allowed under the following terms and conditions:

https://creativecommons.org/licenses/by-nc/4.0/legalcode. Copies of published material are allowed for personal or internal use. Sharing published material for non-commercial purposes is subject to the following conditions:

https://creativecommons.org/licenses/by-nc/4.0/legalcode, sect. 3. Reproducing and sharing published material for commercial purposes is not allowed without permission in writing from the publisher.

\section{(c) (i) (s)}

\section{Benedetto Bruno,,$^{1,2^{\circ}}$ Ralph Wäsch, ${ }^{3}$ Monika Engelhardt, ${ }^{3}$ Francesca Gay, ${ }^{1}$ Luisa Giaccone, ${ }^{1}$ Mattia D'Agostino, ${ }^{1}$ Luis-Gerardo Rodríguez-Lobato, ${ }^{4,5}$ Sophia Danhof, ${ }^{5}$ Nico Gagelmann, ${ }^{6}$ Nicolaus Kröger, ${ }^{6}$ Rakesh Popat, ${ }^{7}$ Niels W C J van de Donk, ${ }^{8}$ Evangelos Terpos, ${ }^{9}$ Meletios A Dimopoulos, ${ }^{9}$ Pieter Sonneveld, ${ }^{10}$ Hermann Einsele ${ }^{5}$ and Mario Boccadoro ${ }^{1}$}

${ }^{1}$ Department of Molecular Biotechnology and Health Sciences, University of Torino and Department of Oncology, Division of Hematology, A.O.U. Città della Salute e della Scienza di Torino, Presidio Molinette, Torino, Italy; ${ }^{2}$ Division of Hematology and Medical Oncology, Perlmutter Cancer Center, Grossman School of Medicine, NYU Langone Health, New York, NY, USA; ; ${ }^{3}$ Department of Hematology, Oncology and Stem Cell Transplantation, University Medical Center, Faculty of Medicine, University of Freiburg, Freiburg, Germany; ${ }^{4}$ Unit of Amyloidosis and Multiple Myeloma, Department of Hematology, Hospital Clínic of Barcelona, Institut d'Investigacions Biomèdiques August Pi i Sunyer (IDIBAPS), Barcelona, Spain; ${ }^{5}$ Division of Medicine II, University Hospital Würzburg, Würzburg, Germany; ${ }^{6}$ Department of Stem Cell Transplantation, University Medical Center Hamburg-Eppendorf, Hamburg, Germany; 'Department of Hematology, University College London Hospitals, London, UK; ${ }^{8}$ Department of Hematology, Amsterdam University Medical Centers, Cancer Center Amsterdam, Location VUmc, Amsterdam, the Netherlands; 'Stem Cell Transplantation Unit, Plasma Cell Dyscrasias Unit, Department of Clinical Therapeutics, School of Medicine, National and Kapodistrian University of Athens, Athens, Greece and ${ }^{10}$ Erasmus MC Cancer Institute, Rotterdam, the Netherlands.

${ }^{\circ}$ Current address: Division of Hematology and Medical Oncology, Perlmutter Cancer Center, Grossman School of Medicine, NYU Langone Health, New York, NY, USA.

\section{ABSTRACT}

himeric antigen receptor (CAR) T cells (CAR-T) have dramatically changed the treatment landscape of B-cell malignancies, providing a potential cure for relapsed/refractory patients. Long-term responses in patients with acute lymphoblastic leukemia and non Hodgkin lymphomas have encouraged further development in myeloma. In particular, B-cell maturation antigen (BCMA)-targeted CAR-T have established very promising results in heavily pre-treated patients. Moreover, CAR-T targeting other antigens (i.e., SLAMF7 and CD44v6) are currently under investigation. However, none of these current autologous therapies have been approved, and despite high overall response rates across studies, main issues such as long-term outcome, toxicities, treatment resistance, and management of complications limit as yet their widespread use. Here, we critically review the most important pre-clinical and clinical findings, recent advances in CAR-T against myeloma, as well as discoveries in the biology of a still incurable disease, that, all together, will further improve safety and efficacy in relapsed/refractory patients, urgently in need of novel treatment options.

\section{Introduction}

Recently engineered chimeric antigen receptors (CAR) have greatly increased anti-tumor effects of CAR T cells (CAR-T). Impressive results have been observed with CD19-directed CAR-T in B-cell lymphoproliferative disorders. ${ }^{1.3}$ In addition, several CAR-T products have been developed for the treatment of multiple myeloma (MM). None has yet been approved, and, despite high overall response (OR) across studies, main issues such as long-term outcomes, toxicities and complications need to be solved to allow their widespread clinical use. In this review, the European Myeloma Network (EMN) group aimed to describe the most important pre-clinical and clinical findings, and recent advances in CAR-T technology against MM that may improve their safety and efficacy. Contents, comments and sugges- 
tions have been incorporated in the manuscript after at least three rounds of discussion resulting in the final unanimously approved version.

\section{Target antigens}

CAR are artificial fusion proteins with a modular design that confer antigen-specificity to $\mathrm{T}$ cells in an human leukocyte antigen (HLA)-independent manner providing intracellular stimulatory signals to enhance survival, proliferation, cytolytic capacity and cytokine production of $\mathrm{T}$ cells. ${ }^{4}$ Figure 1 illustrates the components of CAR constructs. ${ }^{5-8}$ For successful CAR-T therapy, identification of suitable tumor antigens is crucial, since it requires a delicate balance between effectiveness and safety considerations. Ideal antigens should be: (i) highly and homogeneously expressed on tumor cell surface, (ii) expressed at different disease stages, (iii) pivotal in disease pathophysiology, (iv) limited or not shed into the bloodstream, (v) not affected by selective treatment pressure that may cause down-regulation or elimination, and (vi) not expressed on normal tissues..$^{9-10}$ Great progress has been made to identify potential molecules as CAR targets in $\mathrm{MM}$. In this section, we summarize pre-clinical data on the most relevant $\mathrm{MM}$-associated antigens, while a comprehensive overview is provided in Table 1.

\section{B-cell maturation antigen}

The B-cell maturation antigen $(B C M A)$ gene is located on chromosome 16 and the BCMA (aliases: CD269, TNFRSF17) protein, a transmembrane glycoprotein member of the tumor necrosis factor receptor (TNFR) superfamily, is expressed on subsets of B cells (plasmablasts and plasma cells) and up-regulated during B-cell differentiation. It is not expressed on solid organ tissues, hematopoietic cells or naive B cells. ${ }^{11-12}$ Along with two associated receptors (calcium modulator and cyclophilin ligand interactor [TACI] and B-cell activation factor receptor [BAFF$\mathrm{R}]$ ) and its ligands (a proliferation inducing ligand [APRIL] and B-cell activating factor [BAFF]) BMCA regulates maturation, differentiation, and promotes B-cell survival. ${ }^{13-15}$

\section{CAR constructs}

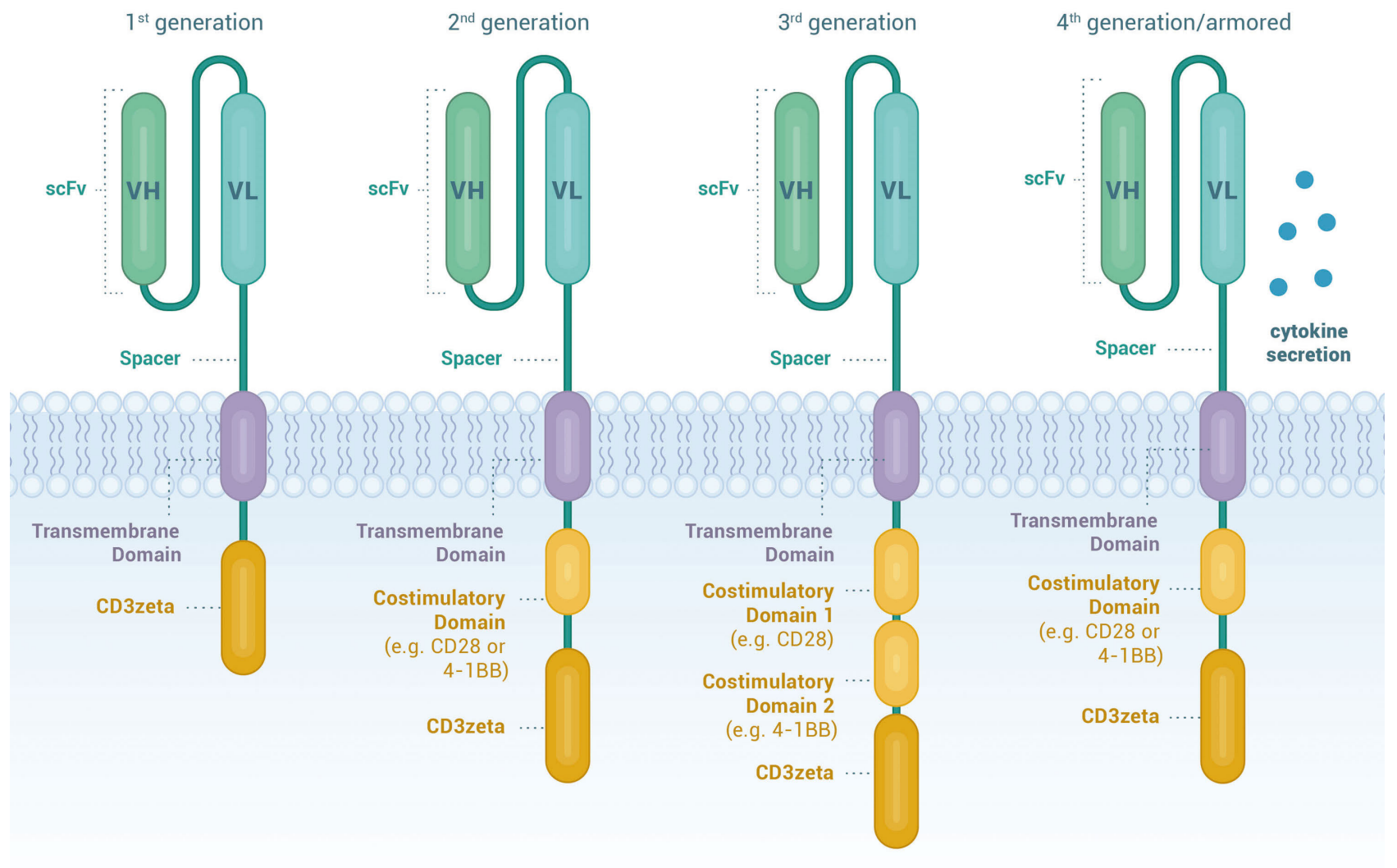

Figure 1. Chimeric antigen receptor T cells. Chimeric antigen receptors (CAR) are designer proteins that redirect $T$ cells towards a defined surface antigen on tumor cells. The CAR construct contains four essential components. The extracellular antigen recognition domain consists of a single chain variable fragment (scFv) commonly derived from the variable domains of the heavy and light chains (VH and VL) of monoclonal antibodies joined by a linker to provide flexibility and solubility and therefore improve antigen recognition and binding capacity. The hinge or spacer moiety based on Ig- (IgG1 or IgG4), CD8- or CD28-derived domains, provides flexibility, stability and the suitable length for optimal access to the target antigen. The transmembrane domain links the extracellular and intracellular domains of the CAR. It is based on CD3 $\zeta$, CD4, CD $8 \alpha, C D 28$ or ICOS moieties, influences CAR stability and signaling and may also be involved in immune synapse arrangement. The last components of the CAR construct are the intracellular signaling domains. The activation domain is typically derived from the CD3 $\zeta$ moiety of the T-cell receptor (first generation CAR), whereas co-stimulatory domains are derived from CD28, 4-1BB, OX40, CD27, or ICOS (second and third generation CAR). Co-stimulation results in intracellular signals that further optimize T-cell function, persistence and proliferation. Through additional genetic modifications, so called "armored" CAR T cells (CAR-T) (fourth generation CAR) secrete cytokines or express ligands to bolster CAR-T function or to overcome the immunosuppressive tumor microenvironment. Taken together, the molecular fine-tuning of pre-existing CAR components can greatly improve cellular migration, foster expansion and persistence of the CART and decrease toxicity. 
Expression of BCMA in malignant plasma cells is enhanced compared to non-malignant cells, though levels are not homogeneous. Its expression is associated with proliferation and survival of tumor cells and contributes to the immunosuppressive bone marrow (BM) microenvironment. ${ }^{15-17} \mathrm{BCMA}$ cleavage by $\gamma$-secretase sheds soluble BCMA (sBCMA) into the bloodstream. ${ }^{18}$ sBCMA may play a role in myeloma pathogenesis, and high sBCMA levels have been associated to worse prognosis. ${ }^{19} \mathrm{BCMA}$ is currently considered the most compelling antigen for targeted immunotherapy. Carpenter et al. reported on the first proof-of-concept using a second generation, CD28 co-stimulated CAR against BCMA in the preclinical setting. BCMA CAR-T specifically recognized the antigen, eradicated in vivo tumors and killed primary myeloma cells, ${ }^{11}$ setting the cornerstone for the first-in-human phase I clinical trial evaluating BCMA CAR-T in MM. ${ }^{20}$

\section{Transmembrane activator, calcium modulator, and cyclophilin ligand interactor}

TACI (TNFRSF13B) is a transmembrane protein that recognizes ligands APRIL, BAFF and calcium modulator and cyclophilin ligand (CAML). It is expressed on subsets of naive and memory B cells, plasma cells, non-germinal center cells, monocytes and dendritic cells. TACI supports growth and survival in myeloma cells, though its expression is lower compared to BCMA..$^{21-23}$ A third-generation APRIL-based CAR recognizing both BCMA and TACI antigens has been engineered. Though this construct demonstrated tumor control in an in vivo model of tumor escape with BCMA $\mathrm{TACI}^{+}$cells, ${ }^{22}$ the AUTO2 trial (clinicaltrials gov. Identifier: NCT03287804) was, however terminated because of lack of efficacy. ${ }^{24}$

\section{CD19}

In most B-cell malignancies, CD19 is highly and uniformly expressed..$^{25-29} \mathrm{MM}$ was traditionally considered mostly CD19 negative with low level CD19 expression attributed to a putative "myeloma stem cell". However, highly sensitive direct stochastic optical reconstruction microscopy (dSTORM) unveiled expression of CD19 on a considerable subset (10-80\%) of myeloma cells in more than two thirds of patients, of whom only one fifth was considered CD19 positive by conventional flow cytome-

Table 1. Potential target antigens for CAR-T therapy for mutiple myeloma.

\begin{tabular}{|c|c|c|c|c|}
\hline Antigen & Expression in MM & $\begin{array}{l}\text { Expression in normal } \\
\text { hematopoietic cells }\end{array}$ & $\begin{array}{l}\text { Expression in healthy solid } \\
\text { organ tissues }\end{array}$ & Development state \\
\hline BCMA & $60-100 \%$ & Late memory B cells, plasma cells & No & Clinical trial \\
\hline TACI & $78 \%$ & $\begin{array}{l}\text { Naïve and memory B cells, plasma } \\
\text { cells, monocytes and dendritic cells }\end{array}$ & No & Clinical trial \\
\hline CD19 & $10-80 \%$ & B-cells, plasma cells & No & Clinical trial \\
\hline SLAMF7 (CD319) & High and uniform expression & $\begin{array}{l}\text { NK-cells, monocytes, macrophages, } \\
\text { dendritic cells, T cells, B cells, } \\
\text { plasma cells }\end{array}$ & No & Clinical trial \\
\hline CD38 & High and uniform expression & $\begin{array}{l}\text { Lymphoid and myeloid cells, } \\
\text { hematopoietic precursors, } \\
\text { thymocytes }\end{array}$ & $\begin{array}{l}\text { Prostatic epithelium, } \\
\text { pancreatic islet cells, } \\
\text { cerebellar Purkinje cells }\end{array}$ & Clinical trial \\
\hline CD44v6 & $43 \%$ in advanced stage & Activated T cells, monocytes & Keratinocytes & Clinical trial \\
\hline GPRC5D & $\geq 50 \%$ in $65 \%$ of patients & B-cells, plasma cells & Hair follicles & Clinical trial \\
\hline CD138 & High expression & Plasma cells & $\begin{array}{l}\text { Epithelial cells, gastrointestinal } \\
\text { tract and hepatocytes }\end{array}$ & Clinical trial \\
\hline NKG2D & Heterogenous & NK, T and $\gamma \delta$ T cells & No & Clinical trial \\
\hline$\kappa$ light chain & к-restricted myeloma cells & Mature B cells & No & Clinical trial \\
\hline CD56 & $\begin{array}{l}\text { High expression, decreased } \\
\text { in extramedullary disease }\end{array}$ & $\mathrm{T}$ and NK cells & $\begin{array}{l}\text { Central and peripheral } \\
\text { nervous system }\end{array}$ & Clinical trial \\
\hline Lewis Y & $50 \%$ & No & Epithelial cells & Clinical trial \\
\hline NY-ESO-1 & $60-100 \%$ & No & No & Clinical trial \\
\hline CD229 (SLAMF3) & $\begin{array}{l}\text { High and homogeneous } \\
\text { expression, probably in myeloma } \\
\text { stem cell }\end{array}$ & T, NK and B cells & No & Preclinical investigation \\
\hline Integrin $\beta 7$ & High expression & $\begin{array}{l}\text { High expression in B cells and } \\
\text { low to moderate expression in } \\
\text { CD } 34^{+} \text {hematopoietic cells }\end{array}$ & No & Preclinical investigation \\
\hline CD70 & $0.2-42 \%$ & $\begin{array}{l}\text { Activated T and B cells, dendritic } \\
\text { cells and plasma cells }\end{array}$ & No & Preclinical investigation \\
\hline CDld & High expression & $\begin{array}{l}\text { Antigen-presenting cells, } \\
\text { thymocytes, B cells, and } \\
\text { hematopoietic stem cells }\end{array}$ & Epithelial cells & Preclinical investigation \\
\hline
\end{tabular}


try. As CAR-T can eliminate cells expressing less than 100 target antigens/cell, CD19 has become a relevant CAR target antigen. In preclinical models, BCMA-CD19 bispecific CAR-T eliminated myeloma cell lines more potently than BCMA- or CD19-directed CAR-T alone..$^{30}$ Due to an offtarget expression limited to B cells, toxicity concerns of (co-)targeting CD19 are limited and clinical evaluation of bispecific CAR-T is ongoing (clinicaltrials gov. Identifier: NCT03455972, NCT03549442).

\section{SLAMF7}

The elotuzumab target antigen signaling lymphocytic activation molecule (SLAM) family member 7 (SLAMF7, aliases: CD319, CS-1, CRACC) is an immunomodulatory transmembrane receptor, initially identified on the surface of natural killer (NK) cells. ${ }^{31}$ It is expressed on a variety of other innate immune cells, ${ }^{32}$ but also $\mathrm{T}$ cells, B cells and plasma cells. ${ }^{31-33}$ Importantly, SLAMF7 is expressed on aberrant plasma cells and its precursor ${ }^{34}$ and confers homing of the myeloma cells to the BM niche. While redirecting $T$ cells against a self-antigen may appear difficult, preclinical experiments demonstrated that it is feasible to generate clinically relevant doses of SLAMF7-directed CAR-T, with or without additional inactivation of the endogenous SLAMF7 gene. ${ }^{33-35}$ In preclinical models, potent anti-myeloma activity was demonstrated, resulting in rapid, comprehensive and sustained cell depletion. ${ }^{33}$ SLAMF7-directed CAR-T eliminated SLAMF7 positive lymphocytes in vitro, while SLAMF7 negative lymphocytes were spared and retained their functions. ${ }^{33}$ Clinical evaluation of SLAMF7 CAR-T with functional safety switches is currently ongoing (clinicaltrials gov. Identifier: NCT03958656, EudraCT Nr.2019-001264-30).

\section{CD38}

Successfully targeting CD38 (cyclic ADP ribose hydrolase, ADPRC1) with daratumumab and isatuximab has led to the development of anti-CD38 CAR-T. CD38 is a transmembrane glycoprotein that functions as an ectoenzyme, adhesion molecule and regulator of migration and signaling. It is expressed on malignant plasma cells, ${ }^{36}$ but low expression can be found on lymphoid and myeloid cells, hematopoietic precursors, ${ }^{37}$ thymocytes, cerebellar Purkinje cells and other tissues. CD38 is an activation marker of $\mathrm{T}$ cells at intermediate or late activation stages. As CD38-directed CAR-T demonstrated great antigenspecific efficacy in preclinical myeloma models, ${ }^{38}$ affinity modification of the CAR was developed as an approach to mitigate on-target, off-tumor toxicity towards other CD38 positive hematopoietic cells. Affinity reduction of the antigen binding domain by a factor of 1,000 enabled selective elimination of myeloma cells with high CD38 expression while sparing normal cells with less pronounced CD38 expression. However, it has been reported that levels of CD38 expression on myeloma cells can decline over the disease course. ${ }^{39}$ In this regard, agents that induce selective modulation of CD38 expression levels, such as all-trans retinoic acid (ATRA) or histone deacetylase (HDAC) inhibitors, ${ }^{40}$ represent a promising group for combination therapy with CD38-directed CAR-T. In order to address the issue of antigen reduction by increasing the potency of the cell product, a novel construct termed "dimeric antigen receptor" (DAR) was developed. In fact, the DAR T cells that incorporate a fragment antigen-bind- ing (Fab) moiety instead of the single chain variable fragment $(\mathrm{scFv})$, demonstrated superior preclinical activity. However, their clinical relevance, and the risk of on-target, off-tumor effects, remains to be determined.

\section{CD44v6}

CD44 glycoproteins are encoded by a highly conserved gene, ${ }^{41}$ but are nevertheless characterized by considerable protein heterogeneity due to post-transcriptional modifications or splicing variants. While CD44 plays a role in physiological processes and is expressed on healthy tissues, ${ }^{42}$ the isoform variant 6 is relatively restricted to malignant cells ${ }^{43,44}$ including plasma cells. In healthy tissues, CD44v6 expression is limited to skin keratinocytes. It is absent on hematopoietic precursor cells, but low level expression can be found on activated $\mathrm{T}$ cells and monocytes. While the development of an anti-CD44v6 immunoconjugate was discontinued due to severe skin toxicities, ${ }^{45}$ preclinical investigation of CD44v6-directed CAR-T showed promising efficacy with no impact on keratinocytes that represent potentially immune-privileged sites. ${ }^{46}$ The clinical relevance of the observed monocyte depletion remains unclear. However, as monocyte-derived cytokines play a relevant role for the pathogenesis of cytokine release syndrome (CRS) and immune effector cell-associated neurotoxicity syndrome (ICANS), a beneficial effect is possible and clinical evaluation is ongoing (clinicaltrials gov. Identifier: NCT04097301).

\section{GPRC5D}

The orphan G protein-coupled receptor, class $C$ group 5 member D (GPRC5D), is expressed ubiquitously in malignant bone marrow plasma cells (500 to 1,000 times higher expression than on normal cells), hair follicles, and in the lung. CAR-T targeting GPRC5D have demonstrated promising preclinical activity, and a phase I clinical trial is ongoing (clinicaltrials gov. Identifier: NCT04555551).

\section{CD229}

CD229, a SLAM family receptor ("SALM3"), is generally expressed on myeloma cells and "precursor" myeloma cells. Its high expression suggests a potential as a target for CAR-T studies have shown that this newly designed CD229 CAR-T has high activity against MM cells, memory B cells and MM stem cells in vitro and in vivo. ${ }^{47}$

\section{Clinical studies}

\section{B-cell maturation antigen-specific chimeric antigen receptor T cells}

The National Cancer Institute group performed the first study with BCMA-specific CAR-T with a CD28 costimulatory domain (murine $\mathrm{scFv}$ ) in heavily pretreated patients. ${ }^{20}$ At the highest CAR-T dose $\left(9 \times 10^{6}\right.$ cells $\left./ \mathrm{kg}\right), 13$ of 16 patients $(81 \%)$ achieved at least partial response (PR) with a median event-free survival of 31 weeks. Other studies confirmed high activity of BCMA CAR-T in this patient subset. ${ }^{48-50}$ Advanced clinical findings have been reported with ide-cel ${ }^{50,51}$ and cilta-cel. ${ }^{48}$ Both therapies received Food and Drug Administration breakthrough designation. In this section, we will discuss these two CAR-T products. CAR-T constructs and main clinical characteristics are summarized in Table 2. 


\section{Ide-cel (bb2121)}

The first-in-man study with ide-cel (CRB-401) evaluated escalating doses of CAR-T $\left(50 \times 10^{6}, 150 \times 10^{6}, 450 \times 10^{6}\right.$, or $800 \times 10^{6}$ in the dose-escalation phase, and $150 \times 10^{6}-450 \times 10^{6}$ in the expansion phase) in extensively pretreated $M M$ (median of six prior therapy lines; $69 \%$ triple-class refractory). ${ }^{51}$ Sixty-two patients were enrolled. At least PR was achieved by $76 \%$ of patients including complete response (CR) in 39\%. All 15 patients with $\geq C R$ who had an assessment for minimal residual disease (MRD) were MRD-negative at the level of $10^{-5}$. Baseline BCMA expression or sBMCA levels did not affect response. There was a trend towards lower response in patients who received $\leq 150 \times 10^{6}$ CAR-T, in those with less in vivo CAR-T expansion, and in those with high-risk cytogenetic abnormalities. Median progression free survival (PFS) was 8.8 months for all patients, and 9.0 months for those who

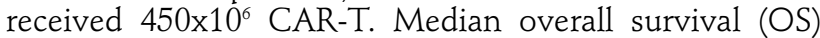
was 34.2 months. Based on these promising results of the phase I trial, a second trial (KarMMa, phase II study) was initiated to evaluate the value of ide-cel in larger numbers of patients who were previously exposed to immunomodulatory drugs (IMiD), a proteasome inhibitor, and a CD38 antibody. ${ }^{50}$ In this study 140 patients were enrolled with a manufacturing success of $99 \%$; 128 of $140(91 \%)$ received CAR-T, whereby $88 \%$ received bridging therapy prior to

Table 2. Ide-cel and Cilta-cel: CAR-T and clinical characteristics

\begin{tabular}{|c|c|c|}
\hline & Ide-cel (bb2121) / KarMMa (phase II) & Cilta-cel (JNJ-4528) / CARTITUDE-1 (phase IB/ II) \\
\hline Antigen-binding domain & scFv (murine) & $\begin{array}{l}\text { Bispecific variable fragments of llama heavy-chain } \\
\text { antibodies; two distinct BCMA epitopes are targeted }\end{array}$ \\
\hline Signaling domains & $\mathrm{CD} 3 \zeta / 4-1 \mathrm{BB}$ & CD3と/4-1BB \\
\hline Vector & Lentiviral & Lentiviral \\
\hline Other features & $\begin{array}{l}\text { Bb21217 uses the same CAR construct as used for ide-cel. } \\
\text { During ex vivo culture a PI3K inhibitor is added to enrich } \\
\text { for CAR-T with memory-like phenotype }\end{array}$ & Bi-epitope BCMA binding confers high avidity binding \\
\hline Lymphodepletion & $\mathrm{Flu} / \mathrm{Cy}$ & $\mathrm{Flu} / \mathrm{Cy}$ \\
\hline CAR-T dose & $150-450 \times 10^{6}$ & Median dose: $0.71 \times 10^{6} / \mathrm{kg}$ \\
\hline Number of patients & 128 (140 patients underwent leukapheresis) & $\begin{array}{l}\text { Data presented for first } 97 \text { (113 patients were } \\
\text { enrolled/apheresed }\end{array}$ \\
\hline Bridging therapy (\%) & 88 & 65 \\
\hline Number of prior therapies (median) & 6 & 6 \\
\hline Triple-class refractory (\%) & 84 & 88 \\
\hline \multicolumn{2}{|c|}{ High-risk cytogenetics (del(17p), t(4;14), or t(14;16) (\%) } & $35 \quad 24$ \\
\hline Extramedullary disease (\%) & 39 & 13 \\
\hline$\geq \mathrm{PR}$ & $\begin{array}{l}150-450 \times 10^{6}: 73 \% \\
150 \times 10^{6}: 50 \% \\
300 \times 10^{6}: 69 \% \\
450 \times 10^{6}: 82 \%\end{array}$ & $97 \%$ \\
\hline$\geq \mathrm{CR}$ & $\begin{array}{l}150-450 \times 10^{6}: 33 \% \\
150 \times 10^{6}: 25 \% \\
300 \times 10^{6}: 29 \% \\
450 \times 10^{6}: 39 \%\end{array}$ & $67 \%$ \\
\hline Median PFS & $\begin{array}{l}150-450 \times 10^{6}: 8.8 \text { months } \\
150 \times 10^{6}: 2.8 \text { months } \\
300 \times 10^{6}: 5.8 \text { months } \\
450 \times 10^{6}: 12.1 \text { months }\end{array}$ & Median PFS: Not reached; 12-month PFS rate: 77\% \\
\hline CRS (all grades) (\%) & 84 & 95 \\
\hline CRS (grade $\geq 3$ ) $(\%)$ & 5 & 4 \\
\hline $\begin{array}{l}\text { Median time to CRS onset } \\
\text { (any grade) (days) }\end{array}$ & 1 & 7 \\
\hline $\begin{array}{l}\text { Median duration of CRS } \\
\text { (any grade) (days) }\end{array}$ & 5 & 4 \\
\hline Neurotoxicity (all grades) (\%) & 18 & 21 (ICANS: 17\%; other neurotoxicity*: 12\%) \\
\hline Neurotoxicity (grade $\geq 3$ ) (\%) & 3 & 10 (ICANS: 2\%; other neurotoxicity: 9\%) \\
\hline $\begin{array}{l}\text { Median time to neurotoxicity onset } \\
\text { (any grade) (days) }\end{array}$ & 2 & ICANS: 8 days; other neurotoxicities*: 27 days \\
\hline $\begin{array}{l}\text { Median duration of neurotoxicity } \\
\text { (any grade) (days) }\end{array}$ & 3 & ICANS: 4 days; other neurotoxicities: 75 days \\
\hline Time to peak CAR-T expansion (days) & 11 & 13 \\
\hline CAR-T persistence 6 months, $\%$ & 59 & 42 \\
\hline
\end{tabular}

*Other neurotoxicities are defined as neurotoxicities occurring after resolution of cytokine release syndrome (CRS) and/or immune effector cell-associated neurotoxicity syndrome (ICANS). PR: partial response; CR: complete response; PFS: progression free survival. 
CAR-T. Patients were highly pretreated with a median of six prior therapy lines and $84 \%$ had triple-class refractory disease (refractory to one protease inhibitor [PI], one $\mathrm{IMiD}$, and a CD38 antibody). At least PR was achieved by $73 \%$ including $\geq C R$ in $33 \%$. MRD-negative $C R$ was achieved in $26 \%$. Median time to response was 1 month. Fifty-four patients, who received $450 \times 10^{6}$ CAR-T, had superior response ( $\geq P R$ : $82 \%$; $\geq C R$ : 39\%; MRD-negative CR: $28 \%$ ) when compared to lower doses. Revised Multiple Myeloma International Staging System (R-ISS) stage 3 disease at enrollment had inferior response, compared to R-ISS stage 1 or 2 . As in the phase I trial, baseline BCMA expression did not affect response to ide-cel. With median follow-up of 13.3 months, overall median PFS was 8.8 months. Median PFS increased with higher CAR-T dose with a median PFS of 12.1 months for patients who received $450 \times 10^{6}$ CAR-T. Patients, who achieved at least CR, also experienced better PFS ( $\geq$ CR: median PFS of 20.2 months; very good partial response [VGPR]: median PFS of 11.3 months; PR: median PFS of 5.4 months; noresponse: 1.8 months). Median OS was 19.4 months. Durable CAR-T persistence was observed up to 1 year: CAR-T were detected at $1,3,6,9$, and 12 months in $99 \%$, $75 \%, 59 \%, 37 \%$, and $46 \%$ respectively. CAR-T expansion was increased at higher doses. In an ongoing phase III study, ide-cel is compared with standard-of-care regimens in patients with 2-4 prior regimens, including IMiD, PI, and CD38 antibody (KarMMa-3). Ide-cel is also evaluated in the multi-cohort KarMMa-2 study, in patients with early relapse after first-line therapy or patients with suboptimal response after autografting (<VGPR).

\section{Cilta-cel (JNJ-4528)}

The CARTITUDE-1 study evaluates cilta-cel (target dose: $0.75 \times 10^{6} \mathrm{CAR}^{+} \mathrm{T} / \mathrm{kg}$ ) in patients exposed to PI, $\mathrm{IMiD}$ and CD38 antibody. Preliminary results were presented at the 2020 ASH conference. Sixteen of 113 patients, who underwent apheresis, were not dosed because of consent withdrawal $(n=5)$, progressive disease $(n=2)$ or death $(n=9)$. The remaining 97 patients had received a median of six prior lines of therapy. Ninetyseven percent of patients achieved at least PR with stringent CR in $67 \%$. Fourty-eight of the 57 patients evaluable for $M R D, 93 \%$ were MRD-negative at the level of $10^{-5}$. Response was independent of baseline BCMA expression. Median time to first response was 1 month. At a median follow-up of 12.4 months, 12-month PFS was 77\%. Peak CAR-T expansion was observed around day 10-14, and CAR-T were observed in $36 \%$ of patients at 3 months of follow-up. ${ }^{52}$ Interestingly, response to cilta-cel was independent of CAR-T expansion and persistence. ${ }^{52}$ In the Chinese LEGEND-2 trial, different conditioning regimens were used, as well as variable CAR-T infusion methods (split vs. single infusion). The Xi'an site, which used cyclophosphamide lymphodepletion therapy and three CAR-T cell infusions (dose: $0.07-2.1 \times 10^{6} / \mathrm{kg}$; median dose: $0.50 \times 10^{6} / \mathrm{kg}$ ), enrolled 57 out of 74 patients. ${ }^{53}$ These patients had received a median of three prior lines of therapy (prior PI and IMiD: 60\%). Overall response rate (ORR) was $88 \%$ with CR in $74 \%$ (median time to response: 1 month). MRD-negative CR was achieved in $68 \%$. At a median follow-up of 25 months, median PFS was 19.9 months for all patients, while it was 28.2 months for those in CR. Median OS was 36.1 months (not reached for patients in CR). Cilta-cel is also being evaluated in a phase
III study (CARTITUDE-4), which compares CAR-T versus pomalidomide, bortezomib and dexamethasone or daratumumab, pomalidomide and dexamethasone in relapsed and lenalidomide-refractory MM. In addition, the ongoing CARTITUDE-2 study is evaluating cilta-cel in different patient populations, including those with early relapse after frontline therapy, prior exposure to a BCMA-targeting drug, and those with $<$ CR post-auto-SCT.

\section{Other B-cell maturation antigen-specific chimeric antigen receptor $\mathrm{T}$ cells}

In order to further improve the activity and/or persistence of CAR-T, several studies are evaluating novel BCMA-targeting CAR-T. Studies include CAR constructs containing a fully human BCMA-specific binding domain to reduce development of humoral and/or cellular immune responses against CAR- $T$, which may impair CAR-T persistence. ${ }^{49,54-56}$ One of these products with a fully human antigen-binding domain is orva-cel (orvacabtagene autoleucel), which is currently evaluated in the phase I/II EVOLVE study. This study shows promising efficacy of orva-cel in heavily pretreated MM (median of six prior lines of therapy; $94 \%$ triple-class refractory). At least PR was achieved in $92 \%$ of 62 patients treated at higher dose levels (300-600x10 CAR-T), with CR in 36\%. Follow-up is ongoing. Treatment was associated with a low incidence of grade $\geq 3$ cytokine release syndrome $(3 \%)$ and grade $\geq 3$ neurotoxicity (3\%). Following CAR-T, there was robust expansion and durable persistence $(69 \%$ of patients had detectable CAR-T at 6 months). Moreover, preclinical studies have shown that enrichment for BCMA-targeting CAR-T displaying a memory-like phenotype leads to improved persistence in mouse models, ${ }^{57}$ which may result in more durable disease control. Bb21217 uses the same CAR molecule as ide-cel, but bb21217 is cultured in the presence of a PI3 kinase inhibitor, which leads to enrichment for CAR-T with a memory-like phenotype. Preliminary results showed efficacy in 69 heavily pretreated patients $(64 \%$ triple-class refractory) with an ORR of $68 \%$ (CR of $29 \%$; median response duration: 17.0 months). Interestingly, a high memory-like $\mathrm{T}$-cell count in the drug product was associated with superior CAR-T expansion and less progression at 6 months. The manufacturing process for orva-cel is also designed to produce CAR-T enriched for central memory T-cell phenotype. ${ }^{56}$ Other trials are evaluating combinations of CAR-T with other drugs to improve activity and durability of response. Based on preclinical data showing that the T-cell stimulatory effects of IMiD enhance the efficacy of CAR-T, ${ }^{58-60}$ several ongoing clinical studies are evaluating the combination of lenalidomide and CAR-T. The combination of BCMA CAR-T with $\gamma$ secretase inhibitors is also investigated, because in vitro studies show that $\gamma$-secretase inhibitors block BCMA cleavage and increase BCMA cell surface expression levels. ${ }^{54,61}$ These results are confirmed in an ongoing clinical study, which shows that gamma secretase inhibition enhances BCMA surface expression on MM cells and reduces soluble $\mathrm{BCMA}$ levels. ${ }^{54}$

\section{CD19-specific CAR-T}

Recent studies showed that MM cells express ultra-low levels of CD19, ${ }^{30}$ moreover MM cells with disease-propagating properties also express CD19. This formed the rationale for the evaluation of CD19-specific CAR-T in 
MM. ${ }^{62}$ One study evaluated CD19 CAR-T following salvage high-dose therapy and autologous transplantation. All ten patients had shown a PFS shorter than 1 year from a previous transplant. Two experienced a longer PFS after transplant plus CD19 CAR-T therapy, compared with first autologous stem-cell transplantation. Only one patient experienced CRS (grade 1). ${ }^{63}$

\section{Chimeric antigen receptor T-cell toxicity in multiple myeloma}

CAR-T may induce several life-threatening side effects such as CRS and ICANS. ${ }^{64}$ Hemophagocytosis and prolonged cytopenias may also occur. CRS mainly consists of fever, hypotension, hypoxia and organ toxicity, which may result in organ failure. ICANS may include several symptoms: impaired concentration, cognitive disorders, confusion, agitation, tremor, lethargy, aphasia, delirium, somnolence, seizures, motor weakness, paresis or signs of intracerebral pressure. ICANS usually occurs during or after CRS and may manifest a biphasic course, in about $10 \%$ of cases up to 4 weeks after CAR-T infusion. A tenpoint neurologic assessment, at least twice a day, using the ICE screening tool is recommended for early detection. ${ }^{64}$ Reported toxicity rates of hallmark studies are illustrated in Table 3. Importantly, a broad consensus statement offering updated comprehensive recommendations for the treatment of toxicities associated with immunotherapies has been recently published. ${ }^{65}$ Though many aspects remain unknown, mechanisms underlying CRS and ICANS have become clearer. Several factors contribute to different toxicity rates. ${ }^{65}$ Moreover, incidence and severity of adverse effects vary between diseases. While the incidence of any grade CRS is comparable between diseases, CRS severity ( $\geq$ grade 3 ) is highest in patients with ALL and lowest in MM. This may partly be explained by disease burden and aggressiveness. In addition, earlier treatment of CAR-T side effects with more experience in recent trials may have contributed to reduce progression to higher grades of toxicity. Unlike CRS, incidence of ICANS is higher in ALL or lymphoma and appears lower in $\mathrm{MM}$ patients. Other factors such as tumor burden, prior treatment, CAR-T constructs and dose administered have been described. Several grading systems have been proposed to assess CRS and ICANS. Recently, the American Society for Transplantation and Cellular Therapy grading system was compared to other grading scores in two adult populations. ${ }^{6}$ Interestingly, incidence of CRS and ICANS were similar in all grading systems. By contrast, only $25 \%$ and $54 \%$ of patients were however assigned to the same severity grade given the discrepancies in scoring adverse symptoms. These differences may also easily lead to inconsistent management guidelines among studies. Overall, efforts should be made to unify grading systems be used across clinical trials.

\section{Improving chimeric antigen receptor T-cell ther- apies in multiple myeloma}

Despite numerous autologous CAR-T products under development ${ }^{67,68}$ and encouraging high response rates, ${ }^{69}$ none have yet been approved, with BCMA remaining the best evaluated target. ${ }^{49,51,69}$ Other limitations are toxicities, resistance mechanisms, availability, and patient management (Table 4). Here we highlight possible strategies for improvement. i $^{701}$

\section{Safety \\ Preventing cytokine release}

The pro-inflammatory interleukin-6 (IL-6) is increasingly acknowledged to play a central role in the pathogenesis of CRS. ${ }^{47}$ A recent study designed a nonsignaling membrane-bound IL-6 receptor (mbaIL6) which was constituted by a scFv derived from an antibody against IL-6, and linked to a transmembrane anchoring peptide. The study identified expression of mball6 on the surface of $T$ cells

Table 3. Toxicity of CAR-T cell treatment in multiple myeloma

\begin{tabular}{|c|c|c|c|c|c|c|c|c|c|}
\hline CAR-T & Construct & Cell dose & Trial & Sponsor & N & Cytopenia $3 / 4$ & CRS 3/4 & ICANS 3/4 & Ref \\
\hline BCMA/CD28 & & $9 \times 10^{6}$ cells / kg bw & First-in-humans & $\mathrm{NIH}$ & 16 & $\begin{array}{l}\text { leucopenia } 94 \% \\
\text { neutropenia } 88 \% \\
\text { thrombopenia } 63 \% \\
\text { prolonged } 13 \%\end{array}$ & $38 \%$ & $6 \%$ & 30 \\
\hline BCMA/4-1BB & & 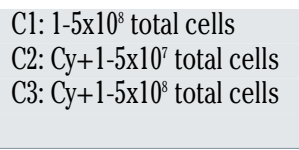 & Phase I & UPenn & 25 & $\begin{array}{l}\text { leucopenia 44\% } \\
\text { neutropenia 44\% } \\
\text { thrombopenia 28\% } \\
\text { prolonged n.r. }\end{array}$ & $32 \%$ & $12 \%$ & 49 \\
\hline BCMA/4-1BB & $\begin{array}{l}\text { LCAR-B38M } \\
\text { (JNJ-4528) }\end{array}$ & med. $0.5 \times 10^{6}$ cells / kg bw & LEGEND-2 & $\begin{array}{c}\text { China } \\
\text { (Phase 1) }\end{array}$ & 57 & $\begin{array}{l}\text { leucopenia 30\% } \\
\text { neutropenia n.r. } \\
\text { thrombopenia } 23 \% \\
\text { prolonged } 16 \%\end{array}$ & $7 \%$ & $0 \%$ & 53 \\
\hline BCMA/4-1BB & JNJ-4528 & med. $0.73 \times 10^{6}$ cells / $\mathrm{kg}$ bw & $\begin{array}{l}\text { CARTITUDE-1 } \\
\text { (Phase I/II) }\end{array}$ & Janssen & 29 & $\begin{array}{l}\text { leucopenia } 59 \% \\
\text { neutropenia } 100 \% \\
\text { thrombopenia } 69 \% \\
\text { prolonged n.r. }\end{array}$ & $7 \%$ & $3 \%$ & $\begin{array}{l}48 \\
68\end{array}$ \\
\hline BCMA/CD28 & bb2121 & $50-800 \times 10^{6}$ total cells & $\begin{array}{l}\text { CRB-401 } \\
\text { (Phase I) }\end{array}$ & BMS / Celgene & 33 & $\begin{array}{l}\text { leucopenia } 58 \% \\
\text { neutropenia } 85 \% \\
\text { thrombopenia } 45 \% \\
\text { prolonged n } 3 \% \text { t } 35 \%\end{array}$ & $6 \%$ & $3 \%$ & 51 \\
\hline
\end{tabular}


which was associated with rapid removal of IL-6 from the culture supernatant. Furthermore, T-cell proliferation increased while the signaling and function of IL- 6 was neutralized. T cells co-expressing mbalL6 and anti-CD19 CAR, neutralized IL-6 derived from macrophages while maintaining antitumor activity in vitro and in a xenograft model. ${ }^{72}$ Thus, CAR-T incorporating the capacity to remove IL-6 may provide new strategies for preventing CRS. Another strategy is the incorporation of "suicide" switches, such as constructs containing a CAR and inducible caspase 9. Administration of a small molecule causing dimerization of inducible caspase 9 resulted in apoptosis and CAR-T-specific depletion. ${ }^{73}$

\section{Reducing off-tumor on-target toxicity}

In order to avoid adverse off-tumor effects, spatial and temporal activity of CAR-T need to be limited. Under this hypothesis, GPRC5D has been proposed as a novel target antigen, expressed on almost all CD138+ cells. ${ }^{74}$ Like BCMA, its expression is restricted to plasma cells, except for hair follicles. Preliminary results of anti-GPRC5D CAR-T showed potent anti-MM efficacy in vitro and in a mouse model, with the encouraging finding that these cells also effectively eradicated $\mathrm{MM}$ after treatment with anti-BCMA CAR-T. Most recently, it was demonstrated that simultaneous targeting of GPRC5D and BCMA could prevent relapse mediated by BCMA escape. Several multitarget constructs were compared and in BCMA-negative disease, dual-target (bicistronic) and pooled approaches exhibited the highest efficacy, whereas for GPRC5D/BCMA-expressing disease, the dual-target appeared to be more efficacious. Mechanistically, expressing two CAR on one cell enhanced the strength of CART/target interactions.

\section{Reducing immunogenicity and simplifying structures}

In order to reduce the immunogenicity of the CAR binding domain, human or humanized scFv have been used more frequently in recent studies, instead of murine sequences. ${ }^{68,75}$ Furthermore, a reduction of immunogenici- ty might be achieved by the incorporation of heavy-chainonly binding domains, which subsequently simplify the structure of the CAR antigen-binding domain without having a light-chain domain. ${ }^{76}$ In general, simplified structures may facilitate better gene expression by transduced $\mathrm{T}$ cells. ${ }^{76,77}$ Moreover, limiting the size of expressed genes is important for the potential expression of $>1$ protein. ${ }^{78,79}$ A recent study demonstrated that CAR with antigenrecognition domains consisting of only a fully human heavy-chain variable domain (FHVH33) in addition to 4$1 \mathrm{BB}$ and $\mathrm{CD} 3 \zeta$ domains mediated comparable cytokine release, reduction in tumor burden, and degranulation in mice when compared to an identical CAR with a conventional scFv. ${ }^{76,80}$ Further investigations identified a crucial contribution of 4-1BB in reducing activation-induced cell death, enabling survival of $\mathrm{T}$ cells expressing FHVH33$\mathrm{CAR}^{76}$

\section{Efficacy \\ Understanding antigen loss}

Some relapses are either antigen-negative or antigenlow. ${ }^{80}$ One study in leukemia mouse models could dissect evidence for CAR promoting reversible antigen loss through a mechanism called trogocytosis. ${ }^{81}$ This mechanism defines an active process of rapid intercellular transfer of membrane fragments and related molecules. The specific target antigen is transferred to $T$ cells resulting in decreased density on tumor cells, leading to declined Tcell activity by boosting fratricide T-cell killing and exhaustion. ${ }^{81}$ These cascades affected CAR constructs that included different costimulatory domains (CD28 or 41BB), and the effect was dependent on antigen density. Thus, it was hypothesized that multi-target CAR-T could overcome these limitations. ${ }^{81}$

\section{Multi-targeting}

T-cells expressing single-chain bispecific CAR are able to prevent antigen escape. 68,22 Moreover, CAR pools combining two single-input CAR-T products have been proposed (Figure 2). Pooling a humanized anti-CD19 and a

Table 4. Limitations and ways to improve CAR-T therapy in multiple myeloma.

\begin{tabular}{|c|c|c|}
\hline & What may limit CAR-T therapy? & How to improve CAR-T therapy? \\
\hline Toxicity & $\begin{array}{l}\text { On-target, on-tumor } \\
\text { On-target, off-tumor }\end{array}$ & $\begin{array}{l}\text { Anti-IL6 treatment and prevention } \\
\text { Safeguard designs incorporating drugs such as rituximab/cetuximab } \\
\text { Tackling immunogenicity } \\
\text { Simplified CAR structures (e.g., heavy-chain-only binding domains) }\end{array}$ \\
\hline Resistance & $\begin{array}{l}\text { Impaired CAR-T expansion/persistence } \\
\text { Immunosuppression induced by BM microenvironment } \\
\text { Antigen loss or downregulation }\end{array}$ & $\begin{array}{l}\text { Multi-targting therapy (dual-target, OR-target, CARpool) } \\
\text { More accurate measurement of expansion/persistence } \\
\text { "Suicide switches" } \\
\text { Combination of immunomodulatory modulation and CAR-T } \\
\text { Senolytic CAR-T (?) } \\
\text { Address trogocytosis } \\
\text { Increase antigen density (e.g. } \gamma \text {-secretase-inhibition for } \\
\text { anti-BCMA therapy) }\end{array}$ \\
\hline Management & Suboptimal recognition and treatment of severe events & $\begin{array}{l}\text { Increase comparability and knowledge sharing of intensive care } \\
\text { unit management and other care settings } \\
\text { Outcome prediction }\end{array}$ \\
\hline Availability & $\begin{array}{l}\text { Lack of scale-up } \\
\text { High costs } \\
\text { No stockpiling } \\
\text { Time }\end{array}$ & $\begin{array}{l}\text { Allogeneic CAR-T } \\
\text { Optimize supply chain models (e.g., intermediate players } \\
\text { for cryopreservation) }\end{array}$ \\
\hline
\end{tabular}

BCMA: B-cell maturation antigen; IL6: interleukin-6; BM: bone marrow. 
murine anti-BCMA CAR- $\mathrm{T}$ was investigated in 22 patients. ${ }^{63}$ The study had a median follow-up of 6 months and reported a high ORR of $95 \%$, with CR of $57 \%$, and relatively low CRS of grades $\geq 3(4 \%){ }^{63}$ Preliminary results of two other CD19/BCMA studies showed similar ORR but lower CR $(22 \%$ and $16 \%){ }^{83,84}$ One study investigated dual-target CAR-T co-expressing two full-length receptors, namely CD38 and BCMA ${ }^{85}$ Median follow-up was 9 months and the ORR was $88 \%$. PFS was $75 \%$ and higher CRS of grades $\geq 3$ were noted compared with tandem CAR (25\%). OR-gate tandem CAR consist of a single CAR structure targeting two antigens with two distinct antigen recognition domains (scFv) linked consecutively with a single signal transducing intracellular domain. ${ }^{82-86} \mathrm{~A}$ recent study using CS1/BCMA tandem CAR-T showed superior CAR expression and function in comparison with T cells co-expressing individual CS1 and BCMA CAR. When compared to the OR-gate (tandem) CAR, dual-target CAR require a much larger genetic payload, leading to poorer transduction efficiency and reduced proliferation. A recent Chinese study using BCMA-CD19 dual FasT CAR-T showed an overall response rate of $93.8 \%$ with median duration of follow up of 7.3 months at cutoff. Importantly, most patients showed high-risk features.$^{87}$ A much more compact genetic footprint may greatly support viral integration, thus product manufacturing, suggesting an advantage for single-chain tandem CAR in relation to dual-targeting. With respect to CARpools, this strategy could avoid poor transduction efficiency. Among these three approaches, mechanistically, CAR pool may be the least effective. ${ }^{80}$

\section{Targeting the tumor microenvironment}

The BM milieu is heavily involved in MM pathogenesis and resistance to treatment. Conflicting data exist on whether monoclonal antibodies against CD38 are effective in the $\mathrm{BM}$ microenvironment, ${ }^{88}$ whereas immunomodulatory agents may be able to overcome these inhibitory effects. ${ }^{89}$ Accordingly, combining these drugs with CAR-T therapy may provide synergistic effects. ${ }^{59}$ Conversely, tissue microenvironment itself is modulated by secretory programs and stable cell-cycle arrest, defined as cellular senescence, which is a tumorsuppressive mechanism. Accumulating aberrant senescent cells create an inflammatory milieu resulting in tissue damage and fibrosis. In order to eliminate these senescent cells, "senolytic" CAR-T have been proposed. ${ }^{90}$ One study discovered the cell-surface protein urokinase-type plasminogen activator receptor (uPAR) being broadly induced during senescence, ${ }^{88}$ and further dissected that anti-uPAR CAR-T efficiently ablated senescent cells in vitro and in vivo, restoring tissue homeostasis in mice with liver fibrosis. ${ }^{90}$ In $M M$, it has been shown that u-PAR contributes to the functioning of cancer-associated fibroblasts during MM progression, ${ }^{91}$ and that higher expression of $\mathrm{u}-\mathrm{PAR}$ was associated with disease progression, worse survival and early extramedullary spread of MM cells. Although it has to be noted that a caveat of senolytic CAR-T are the potential off-target toxicities ${ }^{92}$ these results may encourage the incorporation of cellular strategies specifically addressing the $\mathrm{MM}$ microenvironment.

\section{Availability and management \\ Allogeneic chimeric antigen receptor $T$ cells}

Allogeneic CAR-T may decrease cost and enable broader availability. ${ }^{93}$ Notwithstanding, allogeneic CAR-T bare the risk for graft-versus-host disease (GvHD). For this reason, TALEN- and CRISPR-based gene editing has been introduced to produce allogeneic CAR-T with off-theshelf availability ${ }^{68,93,94}$ One recent study on allogeneic antiBCMA CAR-T used gene editing, namely TALEN, to confer resistance to lymphodepletion and to reduce GvHD risk. ${ }^{95}$ By further incorporating a CD20 mimotope-based switch-off within the CAR, rituximab could be given to eliminate the CAR-T in case of adverse events. Another preclinical approach using similar safety features but antiCS1 CAR-T (UCARTCS1), ${ }^{35}$ specifically degranulated and proliferated in response to MM cells, supporting further evaluation and testing of this universal therapy. Current investigational studies also include (i) the non-viral piggyBac system, aimed at transposing stem cell memory $\mathrm{T}$ cells together with (ii) the Cas-CLOVER ${ }^{\mathrm{TM}}$ gene editing

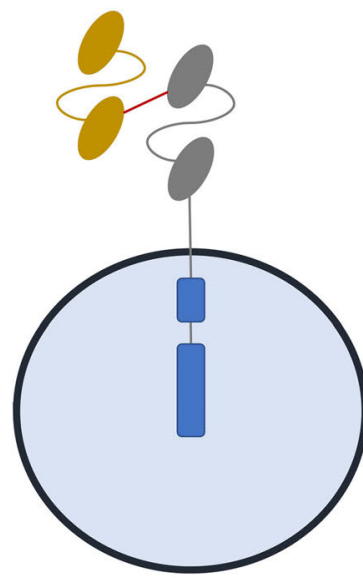

OR-gate

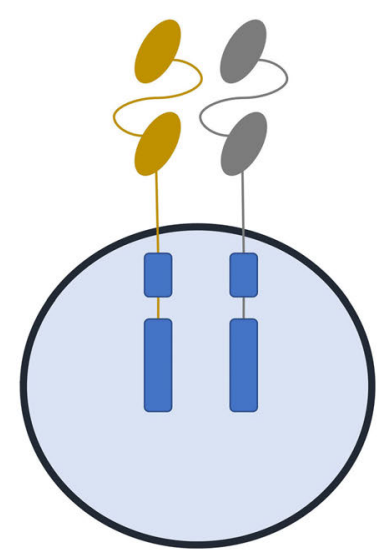

Dual-target

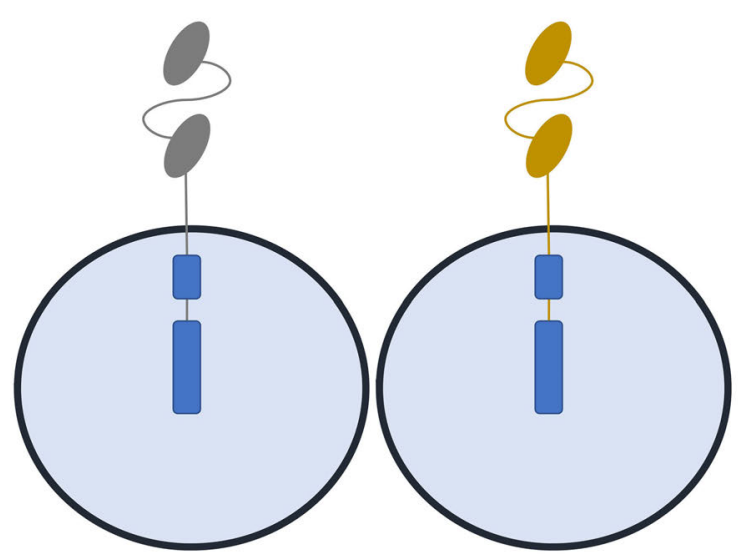

CARpool

Figure 2. Overview of current multi-targeted chimeric antigen receptor T-cell approaches. Multi-targeting may be a mean to improve efficacy of CAR-T. Three major methods could be exploited: OR-gate (tandem) CAR-T: consist of the expression of two different CAR on the same T cell; dual-target CAR-T: consist of encoding two different target specific single-chain variable fragment antibodies on same CAR protein using a single vector; CARpool: involves production of two separate single target CAR-T products infused together or sequentially. 
system consisting of CRISPR guide-RNA and dead Cas9 fused to Clo51 nuclease, and (iii) a nano-particle delivery system carrying the gene for an anti-BCMA Centyrinbased CAR with a fully human binding domain. Rimiducid, a lipid-permeable tacrolimus analogue and protein dimerizer, may be administered for safety switch activation. $^{96}$ Two phase I dose escalation and cohort expansion studies have recently been initiated. The CTX120 (clinicaltrials gov. Identifier: NCT04244656) is using anti-BCMA allogeneic CRISPR-Cas9-engineered T cells and the PBCAR269A (clinicaltrials gov. Identifier: NCT04171843) which applies its own gene editing tool (ARCUS) for GvHD risk reduction.

\section{Integration of chimeric antigen receptor $\mathrm{T}$ cells into clinical routine - FACT-JACIE* standards and EBMT** guidelines}

Since 2018, with version 7.0, the *Joint Accreditation Committee of ISCT and the ${ }^{* *}$ European Bone Marrow Transplantation Group (EBMT) (JACIE) prerequisites for cell therapy accreditation have included standards for infusions of immune-effector cells and CAR-T. The current recommendation is that CAR-T should be administered within the framework of an accredited allogeneic transplant program. The Foundation for the Accreditation of Cellular Therapy (FACT)-JACIE do not cover the manufacturing of CAR-T but do include supply chain and handover of responsibilities when the product is provided by third party. Overall, JACIE standards are structured on the basis of three major functional areas in cellular therapy: cell collection, laboratory processing, and clinical program. All areas required dedicated and highly qualified personnel. Accredited programs for cell therapy must implement a product labeling system that guarantees identification and traceability from collection to manufacturing site and return to clinical units. EBMT recommendations further stress the importance of staff training" and of multidisciplinary approaches with teams who include transplant physicians along with qualified internal medicine sub-specialists after a specific education program. Importantly, CAR-T infusions should be coordinated with intensive care specialists. All accredited centers must implement a policy for rapid escalation of care for critically ill patients including availability of specific drugs (i.e., tocilizumab). Though complications may vary among CAR-T products, they tend to follow a predictable timeline contributing to bed-planning decisions. Recent reports allow designing protocols for anti-infective prophylaxis and common postinfusion complications such as infections and tumor lysis syndrome. ${ }^{98}$ Inevitably, the unfortunate COVID-19 pandemic stresses the importance of scrupulous adherence to recommended hygiene procedures.99 Importantly, an EBMT registry, for all transplant centers accredited for cell therapies, has been created to collect date on efficacy, side effects and clinical outcomes for post-marketing surveillance.

\section{Conclusions}

The clinical role of CAR- $T$ in the current armamentarium of MM treatments remains as yet to be fully determined. Moreover, other promising forms of antibodybased immunotherapies have been added. Despite some limitations of CAR-T therapy experienced in early studies in $\mathrm{MM}$, one advantage of this cellular therapy is the inherent potential to finetune its design. Simpler structures and multi-target approaches may significantly improve efficacy and safety. Constant learning to handle CAR-T therapy may also enable better patient-centered management. Last, long-term outcome studies and specific detection and analysis of CAR-T dynamics in vivo are essential to allow deeper understanding of their inherent functions which will facilitate future designs of improved CAR-T products. However, selecting patients who may most benefit from CAR-T and best timing of their administration still require rather lengthy and thorough clinical investigations. One more challenge that lies ahead will be the cost effectiveness of future commercial products. This issue has already been addressed in patients with lymphoma where cost reductions will be inevitable to make CAR-T sustainable therapies for health care systems. ${ }^{100}$ Despite all remaining open questions and issues that still need to be addressed, and hopefully answered and resolved within the next years, we are now, without any doubt, at the dawn of a new era that will significantly improve patient outcome.

\section{Disclosures}

No conflicts of interest to disclose.

\section{Contributions}

$B B, M E, N W C J D$ designed the review and wrote the manuscript; $L G, M D, F G, E T, L G R L, S D, N G, N K, R P$ and $E T$ provided data and interpretation; MAD, PS, HE and MB reviewed the manuscript.

\section{Funding}

LGRL as BITRECS fellow has received funding from the European Union's Horizon 2020 research and innovation programme under the Marie Sklodowska-Curie grant agreement No 754550 and from "La Caixa" Foundation. SD has received funding from the Mildred Scheel Early Career Center funded by the German Cancer Aid.

\section{References}

1. Maude SL, Laetsch TW, Buechner J, et al. Tisagenlecleucel in children and young adults with B-cell lymphoblastic leukemia. N Engl J Med. 2018;378(5):439-448.

2. Neelapu SS, Locke FL, Bartlett NL, et al. Axicabtagene ciloleucel CAR T-cell therapy in refractory large B-cell lymphoma. N Engl J Med. 2017;377(26):2531-2544.

3. Cerrano M, Ruella M, Perales MA, et al.
The advent of CAR T-cell therapy for lymphoproliferative neoplasms: integrating research into clinical practice. Front Immunol. 2020;11:888.

4. Sadelain M, Brentjens R, Riviere I. The basic principles of chimeric antigen receptor design. Cancer Discov. 2013;3(4):388398.

5. Hudecek M, Lupo-Stanghellini MT, Kosasih PL, et al. Receptor affinity and extracellular domain modifications affect tumor recognition by ROR1-specific chimeric antigen receptor $\mathrm{T}$ cells. Clin Cancer Res. 2013;19(12):3153-3164.

6. Jonnalagadda M, Mardiros A, Urak R, et al. Chimeric antigen receptors with mutated IgG4 Fc spacer avoid fc receptor binding and improve $T$ cell persistence and antitumor efficacy. Mol Ther. 2015;23(4):757768.

7. Kawalekar OU, RS OC, Fraietta JA, et al. Distinct signaling of coreceptors regulates specific metabolism pathways and impacts memory development in CAR T cells. 
Immunity. 2016;44(3):712.

8. Sadelain M, Riviere I, Riddell S. Therapeutic $T$ cell engineering. Nature. 2017;545(7655):423-431

9. Abbott RC, Cross RS, Jenkins MR. Finding the Keys to the CAR: identifying novel target antigens for $\mathrm{T}$ cell redirection immunotherapies. Int J Mol Sci. 2020;21 (2):515.

10. Maude S, Barrett DM. Current status of chimeric antigen receptor therapy for haematological malignancies. $\mathrm{Br} \mathrm{J}$ Haematol. 2016;172(1):11-22.

11. Carpenter RO, Evbuomwan MO, Pittaluga $\mathrm{S}$, et al. B-cell maturation antigen is a promising target for adoptive T-cell therapy of multiple myeloma. Clinical Cancer Res. 2013;19(8):2048-2060.

12. O'Connor BP, Raman VS, Erickson LD, et al. BCMA is essential for the survival of long-lived bone marrow plasma cells. J Exp Med. 2004:199(1):91-98.

13. Mackay F, Tangye SG. The role of the BAFF/APRIL system in B cell homeostasis and lymphoid cancers. Curr Opin Pharmacol. 2004;4(4):347-354.

14. Ng LG, Mackay CR, Mackay F. The BAFF/APRIL system: life beyond B lymphocytes. Mol Immunol. 2005;42(7):763772.

15. Claudio JO, Masih-Khan E, Tang H, et al. A molecular compendium of genes expressed in multiple myeloma. Blood. 2002;100(6): 2175-2186

16. Novak AJ, Darce JR, Arendt BK, et al. Expression of BCMA, TACI, and BAFF-R in multiple myeloma: a mechanism for growth and survival. Blood. 2004;103(2): 689-694.

17. Moreaux J, Legouffe E, Jourdan E, et al. BAFF and APRIL protect myeloma cells from apoptosis induced by interleukin 6 deprivation and dexamethasone. Blood. 2004;103(8):3148-3157

18. Laurent SA, Hoffmann FS, Kuhn PH, et al. gamma-Secretase directly sheds the survival receptor BCMA from plasma cells. Nat Commun. 2015;6:7333.

19. Ghermezi M, Li M, Vardanyan S, et al. Serum B-cell maturation antigen: a novel biomarker to predict outcomes for multiple myeloma patients. Haematologica. 2017; 102(4):785-795.

20. Ali SA, Shi V, Maric I, et al. T cells expressing an anti-B-cell maturation antigen chimeric antigen receptor cause remissions of multiple myeloma. Blood. 2016;128(13): 1688-1700.

21. Mackay F, Schneider P. TACI, an enigmatic BAFF/APRIL receptor, with new unappreciated biochemical and biological properties. Cytokine Growth Factor Rev. 2008;19(34):263-276

22. Lee L, Draper B, Chaplin N, et al. An APRIL-based chimeric antigen receptor for dual targeting of BCMA and TACI in multiple myeloma. Blood. 2018;131(7):746-758.

23. Quinn J, Glassford J, Percy L, et al. APRIL promotes cell-cycle progression in primary multiple myeloma cells: influence of $\mathrm{D}$ type cyclin group and translocation status. Blood. 2011;117(3):890-901.

24. Popat R, Zweegman S, Cavet J, et al. Phase 1 first-in-human study of AUTO2, the first chimeric antigen receptor (CAR) T cell targeting APRIL for patients with relapsed/refractory multiple myeloma (RRMM). Blood. 2019;134(Suppl 1):S3112.

25. Poe JC, Minard-Colin V, Kountikov EI, Haas KM, Tedder TF. A c-Myc and surface CD19 signaling amplification loop promotes B cell lymphoma development and progression in mice. J Immunol. 2012;189 (5):2318-2325

26. Ali S, Moreau A, Melchiorri D, et al. Blinatumomab for acute lymphoblastic leukemia: the first bispecific T-cell engager antibody to be approved by the EMA for minimal residual disease. Oncologist. 2020;25(4):e709-e715.

27. Loffler A, Kufer P, Lutterbuse R, et al. A recombinant bispecific single-chain antibody, CD19 x CD3, induces rapid and high lymphoma-directed cytotoxicity by unstimulated $\mathrm{T}$ lymphocytes. Blood. 2000;95(6):2098-2103.

28. Porter DL, Levine BL, Kalos M, Bagg A, June $\mathrm{CH}$. Chimeric antigen receptor-modified $\mathrm{T}$ cells in chronic lymphoid leukemia. N Engl J Med. 2011;365(8):725-733.

29. Schuster SJ, Svoboda J, Chong EA, et al. Chimeric antigen receptor $T$ cells in refractory B-cell lymphomas. N Engl J Med. 2017:377(26):2545-2554

30. Nerreter T, Letschert S, Götz R, et al. Superresolution microscopy reveals ultra-low CD19 expression on myeloma cells that triggers elimination by CD19 CAR-T. Nat Commun. 2019;10(1):3137.

31. Boles KS, Stepp SE, Bennett M, Kumar V, Mathew PA. 2B4 (CD244) and CS1: novel members of the $\mathrm{CD} 2$ subset of the immunoglobulin superfamily molecules expressed on natural killer cells and other leukocytes. Immunol Rev. 2001;181:234249.

32. Chen J, Zhong MC, Guo H, et al. SLAMF7 is critical for phagocytosis of haematopoietic tumour cells via Mac-1 integrin. Nature. 2017;544(7651):493-497.

33. Gogishvili T, Danhof S, Prommersberger S, et al. SLAMF7-CAR $\mathrm{T}$ cells eliminate myeloma and confer selective fratricide of SLAMF7(+) normal lymphocytes. Blood. 2017;130(26):2838-2847.

34. De Salort J, Sintes J, Llinas L, MatesanzIsabel J, Engel P. Expression of SLAM CD150) cell-surface receptors on human Bcell subsets: from pro-B to plasma cells. Immunol Lett. 2011;134(2):129-136.

35. Mahtur R, Zhang Z, He J, et al. Universal SLAMF7-specific CAR T-cells as treatment or multiple myeloma Blood. 2017;130 (Suppl 1):S502.

36. Harada H, Kawano MM, Huang N, et al. Phenotypic difference of normal plasma cells from mature myeloma cells. Blood. 1993;81(10):2658-2663

37. von Laer D, Corovic A, Vogt B, et al. Loss of CD38 antigen on CD34+CD38+ cells during short-term culture. Leukemia. 2000;14(5):947-948.

38. Drent E, Groen RW, Noort WA, et al. Preclinical evaluation of CD38 chimeric antigen receptor engineered $T$ cells for the treatment of multiple myeloma. Haematologica. 2016;101(5):616-625

39. Nijhof IS, Casneuf T, van Velzen J, et al. CD38 expression and complement inhibitors affect response and resistance to daratumumab therapy in myeloma. Blood. 2016;128(7):959-970.

40. Garcia-Guerrero E, Gotz R, Doose S, et al. Upregulation of CD38 expression on multiple myeloma cells by novel HDAC6 inhibitors is a class effect and augments the efficacy of daratumumab. Leukemia. 2021;35(1):201-214.

41. Ponta H, Sherman L, Herrlich PA. CD44: from adhesion molecules to signalling regulators. Nat Rev Mol Cell Biol. 2003;4(1):3345

42. Zoller M. CD44: can a cancer-initiating cell profit from an abundantly expressed mole- cule? Nat Rev Cancer. 2011:11(4):254-267.

43. Gunthert U, Hofmann M, Rudy W, et al. A new variant of glycoprotein CD44 confers metastatic potential to rat carcinoma cells. Cell. 1991;65(1):13-24.

44. Legras S, Gunthert U, Stauder R, et al. A strong expression of CD44-6v correlates with shorter survival of patients with acute myeloid leukemia. Blood. 1998;91(9):34013413.

45. Tijink BM, Buter J, de Bree R, et al. A phase I dose escalation study with anti-CD44v6 bivatuzumab mertansine in patients with incurable squamous cell carcinoma of the head and neck or esophagus. Clin Cancer Res. 2006;12(20 Pt 1):6064-6072.

46. Casucci M, Nicolis di Robilant B, Falcone L, et al. CD44v6-targeted T cells mediate potent antitumor effects against acute myeloid leukemia and multiple myeloma. Blood. 2013;122(20):3461-3472.

47. Radhakrishnan SV, Luetkens T, Scherer SD et al. CD229 CAR T cells eliminate multiple myeloma and tumor propagating cells without fratricide. Nat Commun. 2020;11 (1):798

48. Madduri D, Berdeja JG, Usmani SZ, et al CARTITUDE-1: phase $1 \mathrm{~b} / 2$ study of ciltacabtagene autoleucel, a B-cell maturation antigen-directed chimeric antigen receptor $T$ cell therapy, in relapsed/refractory multiple myeloma. Blood. 2020;136 (Suppl 1):S22-25.

49. Cohen AD, Garfall AL, Stadtmauer EA, et al. B cell maturation antigen-specific CAR T cells are clinically active in multiple myeloma. I Clin Invest. 2019:129(6):2210-2221.

50. Munshi N, Anderson LD, Jr., Shah N, et al. Idecabtagene vicleucel (ide-cel; bb2121), a BCMA-targeted CAR T-cell therapy, in patients with relapsed and refractory multiple myeloma (RRMM): initial KarMMa results. J Clin Oncol. 2020:38(Suppl):S8503.

51. Yi Lin, Raje NS, Berdeja JG, et al Idecabtagene vicleucel (ide-cel, bb2121), a BCMA-directed CAR T cell therapy, in patients with relapsed and refractory multiple myeloma: updated results from phase 1 CRB-401 study. Blood. 2020;136(Suppl 1):S26-27

52.Zudaire E, Madduri D, Usmani S, et al. Translational analysis from CARTITUDE1 , an ongoing phase $1 \mathrm{~b} / 2$ study of JNJ-4528 BCMA-targeted CAR-T cell therapy in relapsed and/or refractory multiple myeloma (R/R MM), indicates preferential expansion of CD8 + T cell central memory cell subset. Blood. 2019;134(Suppl 1):S928.

53. Wang B, Zhao W, Liu J, et al. Long-term follow-up of a phase 1, first-in-human openlabel study of LCAR-B38M, a structurally differentiated chimeric antigen receptor $T$ (CAR-T) cell therapy targeting B-cell maturation antigen (BCMA), in patients (pts) with relapsed/refractory multiple myeloma (RRMM). Blood. 2019;134(Suppl 1):S579.

54. Cowan A, Pont M, Sather B, et al. Efficacy and safety of fully human Bcma CAR T cells in combination with a gamma secretase inhibitor to increase Bcma surface expression in patients with relapsed or refractory multiple myeloma. Blood. 2019;134(Suppl 1):S204.

55. Li C, Wang J, Wang D, et al. Efficacy and safety of fully human BCMA targeting CAR T-cell therapy in relapsed/refractory MM. Blood. 2019;134(Suppl 1):S929.

56. Mailankody S, Jakubowiak A, Htut M, et al. Orvacabtagene autoleucel (orva-cel), a B-cell maturation antigen (BCMA)-directed CAR T cell therapy for patients (pts) with relapsed/refractory multiple myeloma 
(RRMM): update of the phase $1 / 2$ EVOLVE study (NCT03430011). J Clin Oncol. 2020;38(15 suppl):8504.

57. Alsina M, Shah N, Raje NS, et al. Updated results from the phase I CRB-402 study of anti-Bcma CAR-T cell therapy bb21217 in patients with relapsed and refractory multiple myeloma: correlation of expansion and duration of response with $\mathrm{T}$ cell phenotypes. Blood. 2020;136 (Suppl 1):S25-26.

58. Kuramitsu S, Ohno M, Ohka F, et al. Lenalidomide enhances the function of chimeric antigen receptor $\mathrm{T}$ cells against the epidermal growth factor receptor variant III by enhancing immune synapses. Cancer Gene Ther. 2015;22(10):487-495.

59. Wang X, Walter M, Urak $R$, et al. Lenalidomide enhances the function of CS1 chimeric antigen receptor-redirected $\mathrm{T}$ cells against multiple myeloma. Clin Cancer Res. 2018;24(1):106-119.

60. Works M, Soni N, Hauskins C, et al. AntiB-cell maturation antigen chimeric antigen receptor $\mathrm{T}$ cell function against multiple myeloma is enhanced in the presence of lenalidomide. Mol Cancer Ther. 2019;18(12):2246-2257

61. Pont MJ, Hill T, Cole GO, et al. Y-Secretase inhibition increases efficacy of BCMA-specific chimeric antigen receptor $\mathrm{T}$ cells in multiple myeloma. Blood. 2019;134(19): 1585-1597.

62. Garfall AL, Maus MV, Hwang WT, et al. Chimeric antigen receptor $T$ cells against CD19 for multiple myeloma. N Engl J Med. 2015;373(11):1040-1047.

63. Yan Z, Cao J, Cheng H, et al. A combination of humanised anti-CD19 and antiBCMA CAR $T$ cells in patients with relapsed or refractory multiple myeloma: a single-arm, phase 2 trial. Lancet Haematol. 2019;6(10):e521-e529

64. Lee DW, Santomasso BD, Locke FL, et al. ASTCT consensus grading for cytokine release syndrome and neurologic toxicity associated with immune effector cells. Biol Blood Marrow Transplant. 2019;25(4):625638.

65. Ragoonanan D, Khazal SJ, Abdel-Azim H, et al. Diagnosis, grading and management of toxicities from immunotherapies in children, adolescents and young adults with cancer. Nat Rev Clin Oncol. 2021;18(7): 435-453.

66. Pennisi M, Jain T, Santomasso BD, et al. Comparing CAR T-cell toxicity grading systems: application of the ASTCT grading system and implications for management. Blood Adv. 2020;4(4):676-686.

67. Wäsch R, Munder M, Marks R. Teaming up for CAR-T cell therapy. Haematologica. 2019;104(12):2335-2336

68. Gagelmann N, Riecken K, Wolschke C, et al. Development of CAR-T cell therapies for multiple myeloma. Leukemia. 2020;34 (9):2317-2332

69. Mikkilineni L, Kochenderfer IN. Chimeric antigen receptor T-cell therapies for multiple myeloma. Blood. 2017;130(24):25942602.

70. García-Guerrero E, Sierro-Martínez B, Pérez-Simón JA. Overcoming chimeric antigen receptor (CAR) modified T-cell therapy limitations in multiple myeloma.
Front Immunol. 2020:11:1128.

71. Rafiq S, Hackett CS, Brentjens RJ Engineering strategies to overcome the current roadblocks in CAR T cell therapy. Nat Rev Clin Oncol. 2020;17(3):147-167.

72. Tan AHJ, Vinanica N, Campana D. Chimeric antigen receptor- $T$ cells with cytokine neutralizing capacity. Blood Adv. 2020;4(7):1419-1431

73. Gargett T, Brown MP.The inducible caspase- 9 suicide gene system as a "safety switch" to limit on-target, off-tumor toxicities of chimeric antigen receptor $\mathrm{T}$ cells. Front Pharmacol. 2014;5:235.

74. Smith EL, Harrington K, Staehr M, et al. GPRC5D is a target for the immunotherapy of multiple myeloma with rationally designed CAR T cells. Sci Transl Med. 2019;11(485):eaau7746.

75. Holliger P, Hudson PJ. Engineered antibody fragments and the rise of single domains. Nat Biotechnol. 2005;23(9):1126-1136.

76. Lam N, Trinklein ND, Buelow B, Patterson GH, Ojha N, Kochenderfer JN. Anti-BCMA chimeric antigen receptors with fully human heavy-chain-only antigen recognition domains. Nat Commun. 2020;11(1): 283

77. Kumar M, Keller B, Makalou N, Sutton RE. Systematic determination of the packaging limit of lentiviral vectors. Hum Gene Ther. 2001:12(15):1893-1905.

78. De Munter S, Ingels J, Goetgeluk G, et al Nanobody based dual specific CARs. Int J Mol Sci. 2018;19(2):403.

79. Martyniszyn A, Krahl AC, Andre MC Hombach AA, Abken H. CD20-CD19 bispecific CAR T cells for the treatment of $B$ cell malignancies. Hum Gene Ther. 2017;28(12):1147-1157.

80. Majzner RG, Mackall CL. Tumor antigen escape from CAR T-cell therapy. Cancer Discov. 2018;8(10):1219-1226.

81. Hamieh M, Dobrin A, Cabriolu A, et al. CAR T cell trogocytosis and cooperative killing regulate tumour antigen escape. Nature. 2019:568(7750):112-116.

82. Hegde M, Mukherjee M, Grada Z, et al Tandem CAR T cells targeting HER2 and IL13Ralpha2 mitigate tumor antigen escape. J Clin Invest. 2016;126(8):30363052

83. Garfall AL, Cohen $\mathrm{AD}$, Lacey $\mathrm{SF}$ et al. Combination anti-Bcma and anti-CD19 CAR T cells as consolidation of response to prior therapy in multiple myeloma. Blood. 2019;134(supplement 1):1863.

84. Shi X, Yan L, Shang J, et al. Tandom autologous transplantation and combined infusion of CD19 and Bcma-specific chimeric antigen receptor $\mathrm{T}$ cells for high risk $\mathrm{MM}$ initial safety and efficacy report from a clinical pilot study. Blood. 2018;132(Suppl 1):S1009

85. Li C, Mei H, Hu Y, Guo T, Liu L, Jiang H. A bispecific CAR- $T$ cell therapy targeting $\mathrm{Bcma}$ and CD38 for relapsed/refractory multiple myeloma: updated results from a phase 1 dose-climbing trial. Blood. 2019;134(supplement 1):930.

86. Zah E, Lin MY, Silva-Benedict A, Jensen MC, Chen YY. T cells expressing CD19/CD20 bispecific chimeric antigen receptors prevent antigen escape by malignant B cells. Cancer Immunol Res. 2016;4
(6):498-508

87. Jiang $\mathrm{H}$, Dong $\mathrm{B}$, Gao L, et al. Clinical results of a multicenter study of the first-inhuman dual BCMA and CD19 targeted novel platform fast CAR-T cell therapy for patients with relapsed/refractory multiple myeloma. Blood. 2020;136(Suppl 1):S2526.

88. Chari A, Suvannasankha A, Fay JW, et al Daratumumab plus pomalidomide and dexamethasone in relapsed and/or refractory multiple myeloma. Blood. 2017;130 (8):974-981.

89. Wang $X$, Walter $M$, Urak $R$, et al Lenalidomide enhances the function of CS1 chimeric antigen receptor-redirected $\mathrm{T}$ cells against multiple myeloma. Clin Cancer Res 2018;24(1):106-119.

90. Amor C, Feucht J, Leibold J, et al. Senolytic CAR T cells reverse senescence-associated pathologies. Nature. 2020;583(7814):127 132.

91. Ciavarella S, Laurenzana A, De Summa S et al. u-PAR expression in cancer associated fibroblast: new acquisitions in multiple myeloma progression. BMC Cancer. 2017 17(1):215.

92. Wagner V, Gil J. T cells engineered to target senescence. Nature. 2020;583(7814):37-38.

93. Depil S, Duchateau P, Grupp SA, Mufti G Poirot L. 'Off-the-shelf' allogeneic CAR T cells: development and challenges. Nat Rev Drug Discov. 2020;19(3):185-199.

94. Cong L, Ran FA, Cox D, et al. Multiplex genome engineering using CRISPR/Cas systems. Science. 2013;339(6121):819-823.

95. Sommer C, Boldajipour B, Kuo TC, et al. Preclinical evaluation of allogeneic CAR T cells targeting BCMA for the treatment of multiple myeloma. Mol Ther. 2019;27(6): 1126-1138.

96.Zhou X, Dotti G, Krance RA, et al. Inducible caspase- 9 suicide gene controls adverse effects from alloreplete T cells after haploidentical stem cell transplantation. Blood. 2015;125(26):4103-4113

97. Yakoub-Agha I, Chabannon C, Bader P, et al. Management of adults and children undergoing chimeric antigen receptor $\mathrm{T}$-cell therapy: best practice recommendations of the European Society for Blood and Marrow Transplantation (EBMT) and the Joint Accreditation Committee of ISCT and EBMT (JACIE). Haematologica. 2020;105 (2):297-316

98. Hill JA, Li D, Hay KA, et al. Infectious complications of CD19-targeted chimeric antigen receptor-modified T-cell immunotherapy. Blood. 2018;131(1):121-130.

99. Ljungman P, Mikulska M, de la Camara R, et al. The challenge of COVID-19 and hematopoietic cell transplantation; EBMT recommendations for management of hematopoietic cell transplant recipients, their donors, and patients undergoing CAR T-cell therapy. Bone Marrow Transplant. 2020;55(11):2071-2076

100. Cher BP, Gan KY, Aziz MIA, et al. Cost utility analysis of tisagenlecleucel vs salvage chemotherapy in the treatment of relapsed/refractory diffuse large B-cell lymphoma from Singapore's healthcare system perspective. J Med Econ. 2020;23(11):1321 1329 . 